Carlisle, J. D., and A. D. Chalfoun. 2020. The abundance of Greater Sage-Grouse as a proxy for the abundance of sagebrush-associated songbirds in Wyoming, USA. Avian Conservation and Ecology 15(2):16. https://doi.org/10.5751/ACE-01702-150216

Copyright (C) 2020 by the author(s). Published here under license by the Resilience Alliance.

Research Paper

\title{
The abundance of Greater Sage-Grouse as a proxy for the abundance of sagebrush-associated songbirds in Wyoming, USA
}

\author{
Jason D. Carlisle ${ }^{1,2}$ and Anna D. Chalfoun ${ }^{3}$ \\ ${ }^{1}$ Wyoming Cooperative Fish and Wildlife Research Unit, Department of Zoology and Physiology, Program in Ecology, University \\ of Wyoming, ${ }^{2}$ Western EcoSystems Technology, Inc., ${ }^{3}$ U.S. Geological Survey Wyoming Cooperative Fish and Wildlife Research \\ Unit, Department of Zoology and Physiology and Program in Ecology, University of Wyoming
}

\begin{abstract}
Surrogate-species concepts are prevalent in animal conservation. Such strategies advocate for conservation by proxy, wherein one species is used to represent other taxa to obtain a conservation objective. The efficacy of such approaches has been rarely assessed empirically, but is predicated on concordance between the surrogate and sympatric taxa in distribution, abundance, and ecological requirements. Our objective was to identify whether the abundance of a high-profile umbrella species (Greater Sage-Grouse, Centrocercus urophasianus, hereafter sage-grouse) was associated with the abundance of six other members of the avian community for which it is presumed to be a surrogate, including three sagebrush-obligate and three sagebrush-associated songbird species. We predicted that sage-grouse abundance would align most closely with the breeding abundance of other sagebrush-obligate birds. We used two different indices of sage-grouse abundance for comparisons: field-collected counts of fecal pellets (primarily indexing abundance in the nonbreeding season) and a spatially explicit index of breeding population size. Neither index of sage-grouse abundance was consistently predictive of co-occurring songbird abundance, with one species more abundant (Horned Lark [Eremophila alpestris]) and one species less abundant (Vesper Sparrow [Pooecetes gramineus] ) where sage-grouse pellet counts were higher, and no relationship evident between songbird abundance and the spatially explicit sage-grouse population index. Ours is one of few assessments of the efficacy of sage-grouse as a surrogate species to consider abundance, and not habitat overlap alone. We suggest that the utility of sagegrouse as a surrogate species likely varies across spatial scales. Within the scale examined here (10-15 ha sites), however, indices of sage-grouse abundance were unreliable proxies for the abundance of six declining songbird species.
\end{abstract}

\section{L'abondance du Tétras des armoises comme indicateur de l'abondance de passereaux associés à l'armoise dans le Wyoming, États-Unis}

RÉSUMÉ. Les concepts d'espèces indicatrices sont très répandus dans le domaine de la conservation des animaux. Ces stratégies préconisent la conservation par indicateurs, dans laquelle une espèce est utilisée pour représenter d'autres taxons afin d'atteindre un objectif de conservation. L'efficacité de ces approches a rarement été évaluée de manière empirique, mais elle repose sur la concordance entre le taxon indicateur et les taxons sympatriques en termes de répartition, d'abondance et de besoins écologiques. Notre objectif était de déterminer si l'abondance d'une espèce parapluie hautement préoccupante (le Tétras des armoises, Centrocercus urophasianus, ci-après « tétras ») était associée à l'abondance de six autres membres de la communauté aviaire dont elle serait indicatrice, notamment trois espèces de passereaux dépendantes des armoises et trois espèces de passereaux associées aux armoises. Nous avons prédit que l'abondance des tétras s'alignerait le plus étroitement sur l'abondance des autres oiseaux dépendants des armoises en temps de reproduction. Nous avons utilisé deux indices différents de l'abondance du tétras pour les comparaisons : des comptes de fèces collectées sur le terrain (principalement pour établir l'abondance en dehors de la saison de reproduction) et un indice spatialement explicite de la taille de la population nicheuse. Aucun des deux indices d'abondance du tétras n'a permis de prédire systématiquement l'abondance des passereaux, une espèce ayant été plus abondante (l'Alouette hausse-col [Eremophila alpestris]) et une espèce moins abondante (le Bruant vespéral [Pooecetes gramineus]) là où les comptes de fèces de tétras étaient plus élevés, et aucune relation évidente entre l'abondance des passereaux et l'indice de population du tétras spatialement explicite n'ayant été établie. Notre évaluation est l'une des rares études estimant l'efficacité du tétras comme espèce indicatrice à prendre en compte l'abondance, et non pas seulement le chevauchement des habitats. Nous croyons que l'utilité du tétras en tant qu'espèce indicatrice varie probablement selon les échelles spatiales. Ainsi, à l'échelle que nous avons examinée (sites de 10-15 ha), les indices d'abondance du Tétras des armoises n'étaient pas des indicateurs fiables de l'abondance de six espèces de passereaux en diminution.

Key Words: abundance; conservation by proxy; Greater Sage-Grouse; sagebrush-obligate; songbirds; surrogate species 


\section{INTRODUCTION}

Surrogate-species concepts, e.g., keystone, indicator, flagship, and umbrella species, originally pioneered in conservation biology, have been increasingly adopted in wildlife management and biodiversity conservation strategies (Caro 2010, U.S. Fish and Wildlife Service 2015a). These strategies advocate for conservation by proxy, meaning that one species is used to represent others (hereafter "background species") to obtain a conservation objective (Caro 2010). The efficacy of such approaches is predicated on concordance between the surrogate and the background species in distribution, abundance, ecological requirements, and threats (Simberloff 1998, Caro 2010). Such concordance, however, is typically assumed but not assessed (Simberloff 1998, Cushman et al. 2010).

Much of the conservation efforts in the sagebrush-steppe ecosystems of western North America have focused on the Greater Sage-Grouse (Centrocercus urophasianus, hereafter "sage-grouse"). The conservation concerns of sage-grouse have had a high profile, characterized by long-term declines in occupied habitat, local extirpations, and extensive efforts to conserve the birds and the sagebrush-dominated landscapes on which they depend (detailed in Knick and Connelly 2011). Sage-grouse are protected in Canada under the provisions of the Species at Risk Act, and the U.S. Fish and Wildlife Service has been petitioned at least seven times to protect the species under the U.S. Endangered Species Act (Stiver 2011). The sagebrush steppe is home to nearly 630 other animal and plant species of conservation concern (Rich et al. 2005), many of which are declining, endemic to western shrublands, and have received marginal conservation attention (Paige and Ritter 1999, Knick et al. 2003). The conservation of sagebrush-steppe ecosystems and sagebrushassociated wildlife species via sage-grouse proxy has been suggested repeatedly (Rich and Altman 2001, Rich et al. 2005, Rowland et al. 2006, Hanser and Knick 2011).

Assessments of the utility of sage-grouse as a surrogate species have been predominately based on distributional overlap between the areas managed for sage-grouse and model-predicted suitable habitat of background species (Rich et al. 2005, Rowland et al. 2006, Copeland et al. 2014, Carlisle et al. 2017, 2018a). Such assessments have illuminated the potential for sage-grouse management to affect many species at broad spatial scales; however, the exclusive focus on distributional overlap has been a notable shortcoming in the application and evaluation of surrogate-species concepts (Andelman and Fagan 2000, Branton and Richardson 2014). The local abundance of a species plays a central role in its ecology, shaping inter- and intra-species relationships, broader organization of ecological communities, and risk of extirpation (Andrewartha and Birch 1954, Molles 2005). Likewise, informed conservation efforts are predicated on an accurate understanding of the abundance of an organism (Krausman 2002). Consequently, consideration of the abundance of background species relative to the surrogate species has emerged as an important frontier in the theory and application of surrogate-species conservation strategies (Berger 1997, Caro 2003, Cushman et al. 2010, Branton and Richardson 2014, Donnelly et al. 2017). Because conservation efforts within the sagebrush biome are concentrated within areas of high sagegrouse abundance (Doherty et al. 2010, U.S. Fish and Wildlife Service 2013, Chambers et al. 2017), understanding the relationship between the abundances of sage-grouse and those species for which they are presumed to serve as a proxy will be critical. Our aim was to identify whether sage-grouse abundance was a surrogate for the abundance of six migratory songbird species that breed within the sagebrush steppe.

Many birds that breed in arid shrublands, e.g., sagebrush, and grassland habitats are experiencing steep population declines (North American Bird Conservation Initiative 2016, Rosenberg et al. 2019). We evaluated the relationship between the abundance of sage-grouse and six species of songbirds that co-occur with sage-grouse in sagebrush-steppe habitats during the breeding season: Brewer's Sparrow (Spizella breweri), Sagebrush Sparrow (Artemisiospiza nevadensis), Sage Thrasher (Oreoscoptes montanus), Horned Lark (Eremophila alpestris), Vesper Sparrow (Pooecetes gramineus), and Western Meadowlark (Sturnella neglecta).

Brewer's Sparrows, Sagebrush Sparrows, and Sage Thrashers are almost exclusively restricted to sagebrush habitats during the breeding season and are considered sagebrush-obligate species (Paige and Ritter 1999). Sagebrush-obligate songbirds are species of conservation concern across the sagebrush biome (Paige and Ritter 1999, Knick et al. 2003, Rich et al. 2005). All three species are likely experiencing population declines range-wide according to the Breeding Bird Survey (estimated annual trends of $-4.17 \%,-0.93 \%$, and $-1.20 \%$ for Brewer's Sparrow, Sagebrush Sparrow, and Sage Thrasher, respectively, during 2005-2015; Sauer et al. 2017). Horned Larks, Vesper Sparrows, and Western Meadowlarks are generally associated with grassland habitats during the breeding season (Rosenberg et al. 2016), but also breed within sagebrush habitats and are considered species of concern in sagebrush ecosystems (Rich et al. 2005). Since 1970, range-wide population declines for grassland-associated species have equaled or outpaced those of the sagebrush-obligates, raising substantial concerns about the long-term conservation of grasslandassociated species (Rosenberg et al. 2016, 2019). We predicted that the local abundance of sage-grouse would most closely align with that of the three other sagebrush-obligate species.

\section{METHODS}

\section{Study area and design}

We conducted our study in central Wyoming, USA $\left(42^{\circ} 29^{\prime} \mathrm{N}, 107^{\circ}\right.$ $49^{\prime} \mathrm{W}$; Fig. 1). Wyoming is a core stronghold of fairly intact sagebrush-dominated landscapes (Knick et al. 2003), contains over one-third of known sage-grouse range-wide (Doherty et al. 2010), and the state government has expressed ongoing interest in targeting conservation efforts in areas of high sage-grouse abundance (State of Wyoming 2008, 2011, 2015). Nearly $80 \%$ of our study area was public land administered by the U.S. Bureau of Land Management, and primary land uses included livestock grazing and some low-density energy development. Elevation at study sites ranged from 1715 to $2220 \mathrm{~m}$ (Gesch et al. 2002). The mean annual temperature (summarized from 1981 to 2010) ranged from 5.3 to $7.4^{\circ} \mathrm{C}$, and the mean annual precipitation from 20.0 to $31.1 \mathrm{~cm}$ (PRISM Climate Group 2012). The soil temperature and moisture regime was considered cool and dry, characterized by moderate resilience to disturbance and resistance to invasion of annual grasses (Chambers et al. 2016, Maestas et al. 2016). The vegetation community was primarily sagebrush 
steppe of varying structure and composition. Dominant shrub species included big sagebrush (Artemisia tridentata), greasewood (Sarcobatus vermiculatus), silver sagebrush (A. cana), and black sagebrush (A. nova). Rabbitbrush (Chrysothamnus viscidiflorus and Ericameria nauseosa), spiny hopsage (Grayia spinosa), and saltbush (Atriplex sp.) were also present at some sites. Most (78\%) of the study sites were within the state-designated core population area of sage-grouse (State of Wyoming 2011).

Fig. 1. (A) Location of 18 line-transect clusters surveyed in central Wyoming, USA, 2012-2013. Shading represents the breeding population size of Greater Sage-Grouse (Centrocercus urophasianus), where darker areas had higher density of breeding Greater Sage-Grouse (Doherty et al. 2016). (B) Each cluster contained four parallel line transects (white lines, $\mathrm{n}=72$ transects), each $500 \mathrm{~m}$ in length. Basemap shows aerial imagery, where darker areas indicate higher sagebrush cover. (C) Regional location of study area (black polygon). All maps use the WyLam projection.

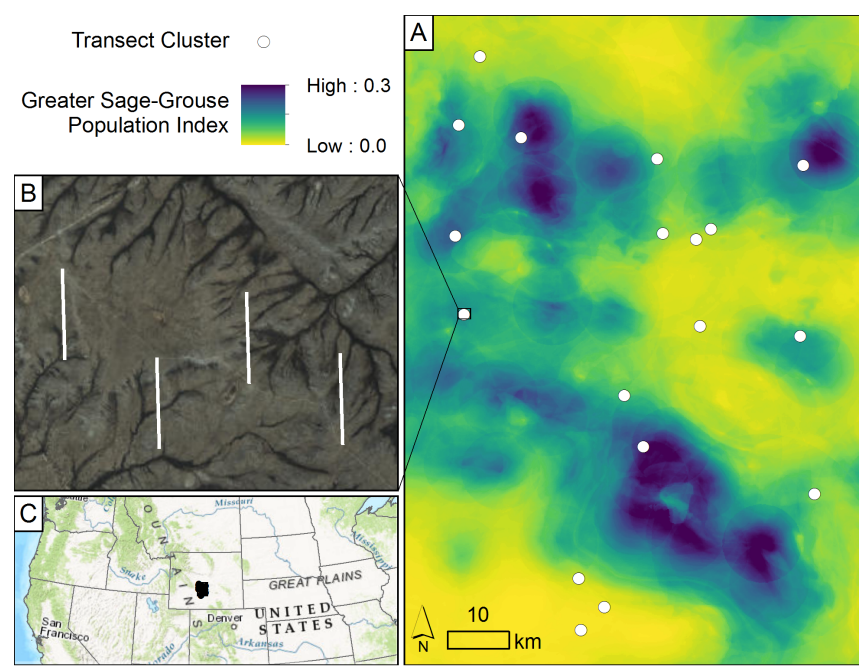

We established 72, 500-m long line transects, in 18 clusters of 4 transects each, following a stratified random sampling scheme (Scheaffer et al. 2012). We used the five levels of a spatially explicit ranking of sage-grouse breeding density (Doherty et al. 2010) as strata. In order of descending sage-grouse breeding density, the highest four rankings were the $25 \%, 50 \%, 75 \%$, and $100 \%$ breeding density thresholds of Doherty et al. (2010); and the lowest was the area outside these breeding core regions but still within the occupied range of sage-grouse (Doherty et al. 2010). We restricted the sampling frame to include areas of public land accessible via two-track dirt roads, excluding all areas within $1 \mathrm{~km}$ of oil/gas well locations or within $100 \mathrm{~m}$ of medium- or high-traffic roads (both paved and unpaved) to control for the potential confounding influence of anthropogenic disturbance (approximately $3200 \mathrm{~km}^{2}$ after exclusions). We allocated 18 clusters unequally across the five strata, with three clusters each in the strata with the highest sage-grouse breeding density (the $25 \%$ breeding core region; Doherty et al. 2010) and the strata representing occupied sage-grouse range outside breeding cores. The remaining strata received four clusters each (the $50 \%, 75 \%$, and $100 \%$ breeding core regions; Doherty et al. 2010). Once the central point of the cluster was selected, we established four parallel line transects, each separated by $500 \mathrm{~m}$. Transects were oriented north-south unless doing so would cause the transect to cross a road or untraversable topography, in which case transects were oriented west-east. Endpoints of transects were manually offset where necessary to preclude transects from crossing a road or untraversable topography (Fig. 1).

\section{Data collection}

We conducted line-transect surveys following a distance-sampling protocol to survey the abundance of songbirds (Buckland et al. 2001). One observer surveyed each transect once per year during the breeding season, between late May and early June of 2012 and 2013. All surveys were conducted between sunrise and 2.5 hours after sunrise on days without precipitation or high winds. A team of two observers was randomly assigned to each transect cluster. All four transects within a cluster were surveyed on the same day, with each observer surveying two transects. We recorded all birds detected by sight or sound, including those detected at any distance, i.e., an unlimited-distance protocol. We recorded the sighting distance, sighting angle, and number of individuals for each detected group of birds (Buckland et al. 2001).

Distance sampling methods make three model assumptions: (1) objects on the line are detected with certainty, (2) distance measurements are exact, and (3) objects are detected at their initial location (Buckland et al. 2015). Although some degree of assumption violation is expected in real-world studies, field methods can be adopted that minimize the bias introduced by failing to meet these assumptions (Buckland et al. 2015). To minimize bias associated with uncertain detection on the line, observers walked quietly and slowly along each transect (average walking speed of $\sim 20 \mathrm{~m} /$ minute), prioritizing the searching of areas near the line (Buckland et al. 2015). To minimize error in distance measurements, we used laser rangefinders (Nikon Prostaff 550, Nikon Inc., Melville, NY, USA; or Bushnell Yardage Pro Sport 450, Bushnell Outdoor Products, Overland Park, KS, USA) to measure sighting distances, and a compass to measure sighting angles. Use of rangefinders generally improves the accuracy of distances (Buckland et al. 2015), but observers were sometimes not able to establish a direct line of sight to a bird detected aurally. In such cases, we estimated the distance that the bird was from a visible point, used the rangefinder to measure the distance to that point, then added or subtracted the additional estimated distance between the visible point and the bird (Hanni, White, and Sparks et al. 2012, unpublished manuscript). To minimize bias associated with bird movement, we measured the distance to where the bird was first detected. We also constrained detection functions fit in the analysis to be monotonically nonincreasing, which can average out some bias due to bird movement (Buckland et al. 2015). Although counting the same individual at multiple transects is not strictly a violation of distance-sampling assumptions (Buckland et al. 2001, 2015), a small number of individuals $(\mathrm{n}=2)$ were detected more than 250 $\mathrm{m}$ perpendicular to the line transect. Because transects were 500 $\mathrm{m}$ apart, such individuals could plausibly be detected twice, once each from adjacent transects. However, given the right-truncation 
distances used in the detection modeling (100 or $150 \mathrm{~m})$ and the territorial nature of songbirds during the breeding season, counting the same individuals at multiple transects was unlikely.

We used two methods to index sage-grouse abundance at each transect. First, we counted sage-grouse fecal pellets (Boyce 1981, Schroeder and Vander Haegen 2011) within an 8-m wide strip along each transect ( $0.4 \mathrm{ha}$ ). Each transect was surveyed for pellets once between late June and early July 2012 by a team of two observers. Observers walked side-by-side $\sim 4 \mathrm{~m}$ apart in a serpentine pattern along the strip, each observer responsible for sighting pellets within $\sim 2 \mathrm{~m}$. Pellet counts provide an estimate of relative animal abundance in an area (Neff 1968, Caughley 1977), and are recommended as an indirect and efficient way to index abundance, especially across large areas (Bull 1981, Krebs et al. 1987). We assumed that the abundance of sage-grouse fecal pellets was correlated with the number of sage-grouse in the area. Such an assumption, implicit in the use of pellet counts for wildlife monitoring has been validated for a growing number of taxa including ungulates, rodents, and lagomorphs (Neff 1968, Krebs et al. 1987, Karels et al. 2004). We did not estimate the probability of detecting sage-grouse pellets within $2 \mathrm{~m}$, however, a distancesampling evaluation of the probability of detecting sage-grouse pellets within $2 \mathrm{~m}$ suggested detectability is high and does not vary substantially across sites with variable vegetative cover (Dahlgren et al. 2006). Field trials based on a mark-resight protocol also suggested that $>80 \%$ of sage-grouse pellets are detected when searching 2-m strips (Timmer et al. 2019). Moreover, the high detectability of sage-grouse pellets at such small distances is regularly assumed in sage-grouse monitoring (Hanser and Knick 2011, Hanser et al. 2011, Schroeder and Vander Haegen 2011). Sage-grouse pellets can persist for up to three years (Boyce 1981), but pellets deposited in fall, winter, and early spring are likely to persist longest because the diet of sagegrouse during that time typically includes more sagebrush (Schroeder and Vander Haegen 2011); therefore, our pellet counts indexed sage-grouse abundance over multiple years and primarily outside the breeding season.

Second, we summarized a spatially explicit index of sage-grouse breeding population size (produced by Doherty et al. 2016) at each transect (Fig. 1). The identification of core areas of high abundance, and the subsequent prioritization of management action within those high-abundance cores, has been a key component of state and federal efforts to prevent further declines in sage-grouse populations (Doherty et al. 2010, U.S. Fish and Wildlife Service 2013). The calculation of this composite index considered both habitat preferences and local abundances of breeding sage-grouse across the Wyoming Basin ecoregion (Doherty et al. 2016). More specifically, the population index was calculated by first modeling breeding habitat presence (point locations of occupied sage-grouse leks) versus absence (pseudoabsence points) as a function of environmental covariates that described the vegetative community, climate, topography, and anthropogenic land uses (Doherty et al. 2016). Second, kernel density functions were applied to the point locations of occupied leks, weighted by the peak count of lekking birds, to highlight concentration areas (Doherty et al. 2016). The breeding habitat model and kernel output were multiplied to form the composite breeding population index (Doherty et al. 2016). Values of the population index were calculated at a $120-\mathrm{m}$ spatial resolution and ranged from 0 to 0.95 , whereas higher values indicated higher densities of breeding sage-grouse (Doherty et al. 2016). We attributed each transect with the mean value of the population index within a $200-\mathrm{m}$ wide strip (10 ha). Spatial data handling and covariate attribution were conducted using the sp (Pebesma and Bivand 2005), rgdal (Bivand et al. 2018), rgeos (Bivand and Rundel 2018), and raster (Hijmans 2018) packages in Program R (R Core Team 2018).

\section{Statistical analysis}

The number of birds counted at a site is the result of two processes: an ecological process that yields the latent abundance state (latent because it is incompletely observed because of detection error; Kéry and Schaub 2012) and an observation process that yields observed counts based on the latent state and some probability of detection < 1 (Kéry and Schaub 2012). We used the two-stage approach to distance sampling analysis, which allows the flexibility to model each process independently and incorporates the uncertainty in estimating both processes into the final results (Buckland et al. 2009, 2015). The first stage was concerned with estimating the detection probability in relation to covariates and generating a year- and site-specific estimate of density that accounted for imperfect detection. The second stage focused on modeling those estimated songbird densities in relation to sagegrouse-related covariates using a regression model. We analyzed the data for each songbird species separately and converted estimates of songbird abundance to density per standard unit area to aid in interpretation (Caughley 1977). All continuous predictor variables were standardized prior to model fitting to have a mean of 0 and standard deviation of 1 to aid in convergence of parameter estimates. We refer to each transect as a site, but we accommodated the nonindependence of transects within the same cluster.

\section{Stage 1: detection models}

The goal of stage one of the analysis was to estimate a year- and site-specific density for each songbird species by estimating the detection probability and inflating the observed counts of songbirds. Depending on the species, we followed either the multiple-covariate or conventional (no covariates) distance sampling method (Buckland et al. 2001, 2015) and fit detection functions using the Rdistance package (McDonald et al. 2019) in Program R (R Core Team 2018). Differences in site-specific habitat structure or observer skill can create heterogeneity in the detectability of animals in field settings (White 2005, Kellner and Swihart 2014). We therefore considered bare ground cover (a measure of habitat openness) and observer $(n=10)$ as site-level covariates in the detection process in our distance-sampling analyses. We attributed each transect with the average bare ground cover $(\%)$ within a $200-\mathrm{m}$ wide strip along the transect (10 ha) using a spatially explicit dataset of ground cover derived from remote sensing (30-m spatial resolution; Homer et al. 2012). We prepared the songbird detection data for analysis by truncating approximately $5 \%$ of the most-distant detections (Buckland et al. 2001), applying a right-truncation distance of $100 \mathrm{~m}$ for Brewer's Sparrow, Sagebrush Sparrow, Horned Lark, and Vesper Sparrow, and $150 \mathrm{~m}$ for Sage Thrasher and Western Meadowlark.

We used an information theoretic model-selection approach (Burnham and Anderson 2002) to compare candidate detection models and select the best-supported combination of key function 
(the form of the relationship between detection probability and distance; half-normal or hazard rate) and covariates that influenced detectability. For the three most-commonly detected species (Brewer's Sparrow, Horned Lark, and Vesper Sparrow), the candidate model set included eight models (four sets of covariates $\times$ two key functions), including models that allowed for heterogeneity in detection probability $(P)$ due to habitat structure or observer, and models that assumed $P$ was constant (Appendix 1). For the remaining three species, preliminary analyses revealed instability in model convergence and parameter estimation for more-highly parameterized models. We therefore limited the candidate model set to simpler model structures for these species. The candidate model set for Sage Thrasher was restricted to four models (two sets of covariates $\times$ two key functions), including models that allowed for heterogeneity in $P$ due to habitat structure and models that assumed $P$ was constant (Appendix 1). The candidate model set for Sagebrush Sparrow and Western Meadowlark was restricted to two models (one set of covariates $\times$ two key functions), those that assumed $P$ was constant (Appendix 1). We ranked each model based on the second-order variant of Akaike's Information Criterion (AICc; Burnham and Anderson 2002) and estimated the year- and sitespecific probability of detection for each transect for each species based on the top-ranked model. To summarize the detectability of each species, we calculated the mean $P$ across all detected individuals of the species, whereby $P$ varied by individual if the detection function included covariates.

\section{Stage 2: abundance models}

In stage two of the analysis, we estimated the relationship between the sage-grouse-related covariates and songbird densities while accounting for imperfect detection. We fit a count regression model for each species, with the response variable being the observed count of individuals and the probability of detection estimated in stage one included as an offset term to effectively model songbird density corrected for detectability (Buckland et al. 2009, 2015). Although it was unlikely that the same individual songbird was detected at multiple sites, songbird abundances at nearby sites were likely not independent because of spatial autocorrelation. We accounted for this nonindependence by using a generalized linear mixed model (GLMM) as our count regression model, including a random intercept effect for each cluster (Zuur et al. 2009). We fit GLMMs using the glmmTMB package (Brooks et al. 2017) in Program R (R Core Team 2018) and used the bbmle package (Bolker and R Core Team 2017) to calculate AICc-related statistics.

Our primary objective was to estimate the strength of the relationship between each of the two variables describing sagegrouse abundance, i.e., the population index and pellet count, and the abundance of each songbird species. The two sage-grouserelated variables were not highly correlated (Pearson's correlation coefficient $=0.18)$, so we included both in the same model. To control for annual variation in songbird abundance between study years, we also included year as a fixed effect in the model. A Poisson distribution is often assumed in count regression models, but biological count data often exhibit a mean-variance relationship or frequency of zeroes not well represented by the Poisson distribution (Zuur et al. 2009, Kéry 2010). In addition to Poisson, we fit GLMMs that assumed the Negative Binomial (NB), zero-inflated Poisson (ZIP), or zero-inflated Negative
Binomial (ZINB) distribution (Zuur et al. 2009, Kéry 2010) and used an information theoretic model-selection approach (Burnham and Anderson 2002) to select which of four distributions had highest support. The candidate model set therefore included four models (one set of covariates $\times$ four distributions) for each species. For models that included an overdispersion parameter (NB and ZINB) or a zero-inflation parameter (ZIP and ZINB), these parameters were assumed to be constant across sites. To interpret the relationship between sage-grouse-related variables and songbird density on the original, unstandardized scale of each predictor variable, we unstandardized parameter estimates using the expression $\beta_{X} \times$ $\mathrm{SD}(X)$, then back-transformed the unstandardized parameter estimates using the inverse of the $\log$ link.

\section{Propagating uncertainty}

The GLMMs treat the estimated offset term as if it is a known constant, but it is an estimate with some uncertainty (Buckland et al. 2009, 2015). Ignoring this uncertainty would cause the variance estimates for the GLMM coefficients to be biased low (Buckland et al. 2009, 2015). We implemented 2000 iterations of a nonparametric bootstrap to appropriately propagate uncertainty from stage 1 to stage 2 of the analysis via the offset term. In each iteration of the bootstrap, we resampled the transect clusters with replacement, including all transects and years associated with each resampled cluster (Manly 2006). We then reran both stages of the analysis on each bootstrap resample for each species, refitting the top-ranked detection model and topranked GLMM identified using the original sample data. We calculated a $95 \%$ confidence interval (CI) for each parameter on the linear scale using the percentile method (Manly 2006) and considered CIs that contained zero on the linear scale to indicate weak evidence of an effect. To visualize the relationship between sage-grouse-related variables and songbird density, we predicted the back-transformed songbird density across the range of each sage-grouse-related variable while holding the other sage-grouserelated variable at its mean and generated a point-wise $95 \% \mathrm{CI}$ on the back-transformed scale using the percentile method (Manly 2006). Parallel processing of bootstrap replicates was accomplished using the snow (Tierney et al. 2016) and snowfall (Knaus 2015) packages in Program R (R Core Team 2018).

\section{RESULTS}

We conducted 144 line transect surveys during 2012-2013 and observed 2755 individuals of 27 bird species. Our study species were the six most-commonly detected species, accounting for 95.8\% of individuals observed: Horned Lark $(n=1128,40.9 \%)$, Brewer's Sparrow $(\mathrm{n}=827,30.0 \%)$, Vesper Sparrow $(\mathrm{n}=385$, $14.0 \%)$, Sage Thrasher $(\mathrm{n}=170,6.2 \%)$, Sagebrush Sparrow $(\mathrm{n}=$ $74,2.7 \%)$, and Western Meadowlark $(n=56,2.0 \%)$. The transectlevel summaries of the sage-grouse population index ranged from 0.00 to 0.25 (mean $=0.09, \mathrm{SD}=0.07)$, and the observed counts of sage-grouse pellets ranged from 0 to 2103 (mean $=216.99$, SD $=366.06$ ). The transect-level summaries of bare-ground cover used to account for the influence of habitat structure in the detection process ranged from 30.69 to $81.15 \%$ (mean $=61.33 \%$, $\mathrm{SD}=12.03 \%)$.

The best-supported detection model for three species indicated that detectability varied by observer or habitat structure and observer, with the best-supported model for the remaining three 
Table 1. Top-ranked distance-sampling models and estimated detection probabilities (P) from line-transect surveys for songbird abundance in central Wyoming, USA, 2012-2013. All transects were $500 \mathrm{~m}$ long, so a 100 -m strip half-width equates to a 10 ha survey area, and a $150-\mathrm{m}$ strip half-width equates to a 15 ha survey area.

\begin{tabular}{|c|c|c|c|c|}
\hline Species & Strip half-width (m) & Model $^{\dagger}$ & $\mathrm{Key}^{*}$ & $P^{\S}$ \\
\hline $\begin{array}{l}\text { Brewer's Sparrow } \\
\text { Spizella breweri }\end{array}$ & 100 & $P \sim$ BareGround + Observer & half-normal & 0.52 \\
\hline $\begin{array}{l}\text { Sagebrush Sparrow } \\
\text { Artemisiospiza nevadensis }\end{array}$ & 100 & $P \sim 1$ & half-normal & 0.64 \\
\hline $\begin{array}{l}\text { Sage Thrasher } \\
\text { Oreoscoptes montanus }\end{array}$ & 150 & $P \sim 1$ & hazard rate & 0.69 \\
\hline $\begin{array}{l}\text { Horned Lark } \\
\text { Eremophila alpestris }\end{array}$ & 100 & $P \sim$ BareGround + Observer & hazard rate & 0.50 \\
\hline $\begin{array}{l}\text { Vesper Sparrow } \\
\text { Pooecetes gramineus }\end{array}$ & 100 & $P \sim$ Observer & half-normal & 0.51 \\
\hline $\begin{array}{l}\text { Western Meadowlark } \\
\text { Sturnella neglecta }\end{array}$ & 150 & $P \sim 1$ & half-normal & 0.66 \\
\hline
\end{tabular}

species indicating that detectability was constant across sites (Table 1, Appendix 1). The species-level means of $P$ ranged from 0.50 to 0.69 , with Brewer's Sparrows, Horned Larks, and Vesper Sparrows being slightly less detectable than Sagebrush Sparrows, Sage Thrashers, and Western Meadowlarks (Table 1). The bestsupported abundance model assumed the Poisson distribution for three species, the NB distribution for one species, and the ZINB distribution for two species (Table 2, Appendix 2).

The point estimate for the relationship between the sage-grouse population index and songbird abundance was positive for five species and negative for one; however, in all cases the $95 \%$ CIs suggested uncertainty in the direction of the effect (Table 3, Figs. $2,3)$. The point estimate for the relationship between the sagegrouse pellet count and songbird abundance was positive for three species and negative for three. Again, however, the 95\% CIs suggested uncertainty in the direction of the effect for four species. Horned Lark and Vesper Sparrow exhibited differing relationships with sage-grouse pellet count. For every additional 500 sage-grouse pellets, Horned Lark density increased by a relative $8.83 \%$ and Vesper Sparrow density decreased by a relative $23.81 \%$ (Table 3, Figs. 2, 3). The abundance of sagebrush-obligate species was higher in 2013 than in 2012, but consistent between years for the grassland-associated species (Table 2).

\section{DISCUSSION}

Surrogate-species approaches are potentially useful tools in conservation. For these approaches to be effective, however, the distribution and abundance of the surrogate species must serve as a reliable proxy for the distribution and abundance of the background species it is meant to represent. The Greater SageGrouse is a year-round and wide-ranging resident of the North American sagebrush steppe, and often assumed to be an umbrella species for the conservation and management of other sagebrushassociated species (Dinkins and Beck 2019, Timmer et al. 2019). We evaluated the abundance of six migratory songbird species in relation to two indices of sage-grouse abundance that differed in
Fig. 2. Parameter estimates describing the relationships between Greater Sage-Grouse (Centrocercus urophasianus) and songbird abundance in central Wyoming, USA, 2012-2013. Both predictor variables were standardized to have a mean of 0 and standard deviation of 1 prior to model fitting, and estimates are presented on the linear scale. Error bars indicate $95 \%$ confidence intervals based on a nonparametric bootstrap. See Table 1 for species scientific names.

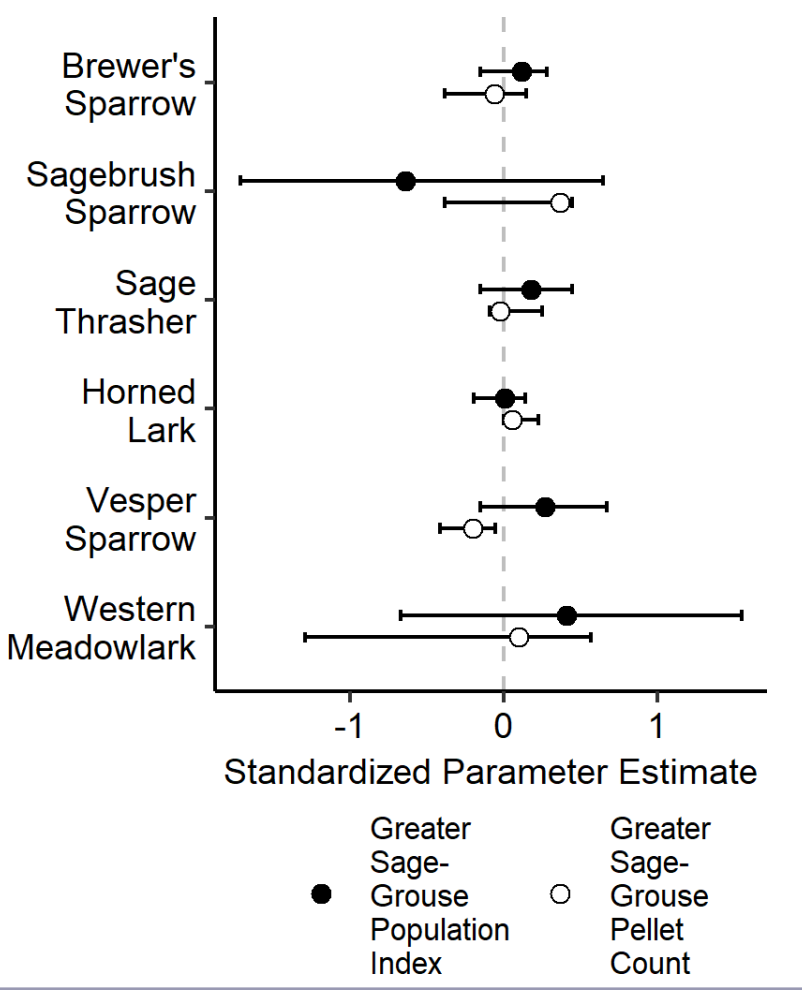


Table 2. Top-ranked abundance models and parameter estimates describing the relationships between Greater Sage-Grouse (Centrocercus urophasianus) and songbird abundance in central Wyoming, USA, 2012-2013. All models were formulated as N PopulationIndex + PelletCount + Year $+(1 \mid$ Cluster $)$, with potentially different response variable distributions. Predictor variables were standardized to have a mean of 0 and standard deviation of 1 prior to model fitting, and estimates are presented on the linear scale. Parenthetical values are 95\% confidence intervals based on a nonparametric bootstrap. The overdispersion and zero-inflation terms are N/A for GLMMs that did not include these terms. See Table 1 for species scientific names.

\begin{tabular}{|c|c|c|c|c|c|c|c|}
\hline Species & Distribution $^{\dagger}$ & Intercept & $\begin{array}{c}\text { Sage-grouse } \\
\text { Population Index }\end{array}$ & Sage-grouse Pellets & Year 2013 & Overdispersion & Zero-inflation \\
\hline Brewer's Sparrow & ZINB & $\begin{array}{c}-0.16 \\
(-0.51,0.08)\end{array}$ & $\begin{array}{c}0.12 \\
(-0.15,0.28)\end{array}$ & $\begin{array}{c}-0.06 \\
(-0.38,0.15)\end{array}$ & $\begin{array}{c}0.46 \\
(0.15,0.80)\end{array}$ & $\begin{array}{c}1.85 \\
(1.22,3.05)\end{array}$ & $\begin{array}{c}-2.14 \\
(-4.83,-1.59)\end{array}$ \\
\hline Sagebrush Sparrow & $\mathrm{P}$ & $\begin{array}{c}-4.42 \\
(-6.41,-3.61)\end{array}$ & $\begin{array}{c}-0.64 \\
(-1.71,0.65)\end{array}$ & $\begin{array}{c}0.37 \\
(-0.38,0.45)\end{array}$ & $\begin{array}{c}1.22 \\
(0.41,1.92)\end{array}$ & N/A & N/A \\
\hline Sage Thrasher & $P$ & $\begin{array}{c}-2.64 \\
(-3.22,-2.21)\end{array}$ & $\begin{array}{c}0.18 \\
(-0.15,0.45)\end{array}$ & $\begin{array}{c}-0.02 \\
(-0.09,0.25)\end{array}$ & $\begin{array}{c}0.56 \\
(0.15,1.08)\end{array}$ & N/A & N/A \\
\hline Horned Lark & ZINB & $\begin{array}{c}0.44 \\
(0.10,0.68)\end{array}$ & $\begin{array}{c}0.01 \\
(-0.19,0.14)\end{array}$ & $\begin{array}{c}0.06 \\
(0.00,0.23)\end{array}$ & $\begin{array}{c}0.05 \\
(-0.21,0.34)\end{array}$ & $\begin{array}{c}1.60 \\
(1.07,2.39)\end{array}$ & $\begin{array}{c}-3.10 \\
(-8.66,-2.27)\end{array}$ \\
\hline Vesper Sparrow & NB & $\begin{array}{c}-1.11 \\
(-1.64,-0.68)\end{array}$ & $\begin{array}{c}0.27 \\
(-0.15,0.67)\end{array}$ & $\begin{array}{c}-0.20 \\
(-0.41,-0.05)\end{array}$ & $\begin{array}{c}0.43 \\
(-0.26,1.04)\end{array}$ & $\begin{array}{c}-0.20 \\
(-0.46,0.37)\end{array}$ & N/A \\
\hline $\begin{array}{l}\text { Western } \\
\text { Meadowlark }\end{array}$ & $\mathrm{P}$ & $\begin{array}{c}-5.06 \\
(-7.27,-4.21)\end{array}$ & $\begin{array}{c}0.41 \\
(-0.67,1.55)\end{array}$ & $\begin{array}{c}0.10 \\
(-1.29,0.57)\end{array}$ & $\begin{array}{c}0.80 \\
(-0.09,1.56)\end{array}$ & N/A & N/A \\
\hline
\end{tabular}

${ }^{\top}$ Response variable distribution $(\mathrm{P}=$ Poisson, NB = Negative Binomial, ZIP = zero-inflated Poisson, ZINB = zero-inflated Negative Binomial) with the lowest AICc value. See Appendix 2 for tables detailing the AICc model-selection results for each species.

Table 3. Parameter estimates describing the relationships between Greater Sage-Grouse (Centrocercus urophasianus) and songbird abundance in central Wyoming, USA, 2012-2013. Estimates are presented on the back-transformed scale of songbird density. Parenthetical values are $95 \%$ confidence intervals based on a nonparametric bootstrap. Estimates reflect a 0.1 unit increase in the Greater Sage-Grouse population index or an additional 500 Greater Sage-Grouse fecal pellets. See Table 1 for species scientific names.

\begin{tabular}{lcc}
\hline \hline Species & $\begin{array}{c}\text { Sage-grouse Population } \\
\text { Index }\end{array}$ & Sage-grouse Pellets \\
\hline Brewer's Sparrow & $1.18(0.82,1.46)$ & $0.92(0.59,1.23)$ \\
Sagebrush Sparrow & $0.42(0.10,2.41)$ & $1.66(0.60,1.86)$ \\
Sage Thrasher & $1.27(0.81,1.84)$ & $0.97(0.89,1.42)$ \\
Horned Lark & $1.01(0.77,1.21)$ & $1.09(1.00,1.37)$ \\
Vesper Sparrow & $1.44(0.82,2.48)$ & $0.76(0.57,0.93)$ \\
Western & $1.75(0.40,8.22)$ & $1.14(0.17,2.17)$ \\
Meadowlark & & \\
\hline
\end{tabular}

their derivation, spatial resolution, and the seasonal period represented, in central Wyoming, USA. We found little concordance between indices of sage-grouse abundance and the abundance of sagebrush-associated songbird species, all of which are also experiencing population declines. Only one of six songbird species (Horned Lark) had higher abundance at sites with higher sage-grouse abundance as quantified by one of the sage-grouse indices, and no species showed a positive relationship with both indices. Moreover, the abundance of Vesper Sparrows was lower at sites with higher sage-grouse abundance as quantified by one of the sage-grouse indices. Finally, the abundance of four of six songbird species had no discernable relationship with either index of sage-grouse abundance.
The indices of sage-grouse abundance were inconsistent proxies for the abundance of the three sagebrush-obligate songbird species, the group we predicted to have the highest concordance with sage-grouse based on their shared dependency on sagebrush habitats. One possible explanation for the lack of positive relationships between sagebrush songbird abundance and the sage-grouse population index is that our transects did not sample enough area at the upper end of the index, which ranged from 0 to 0.95 throughout the broader Wyoming Basin Ecoregion compared to 0 to 0.25 when averaged within $200 \mathrm{~m}$ of our transects. Our transects were randomly placed a priori across the five levels of a spatially explicit ranking of sage-grouse breeding density (Doherty et al. 2010).

Our assessment of sage-grouse as a surrogate species is one of only a few (e.g., Rich et al. 2005, Donnelly et al. 2017, Timmer et al. 2019) to consider the abundance of background species, and not solely distributional overlap. Whereas Timmer et al. (2019) similarly reported mixed associations between sagebrush songbird abundance and modeled sage-grouse occurrence in northwest Colorado, our findings contrast with the results of Rich et al. (2005) and Donnelly et al. (2017), which were conducted across broader spatiotemporal extents. The relative abundances of Brewer's Sparrows, Sagebrush Sparrows, and Sage Thrashers were all correlated with that of sage-grouse when summarized using 30 years of Breeding Bird Survey (BBS) data across sagebrush-associated ecoregions (Rich et al. 2005). Additionally, a comparison of more-recent BBS counts and sage-grouse lek data across the western U.S. revealed that the density of Brewer's Sparrows, Sagebrush Sparrows, and Sage Thrashers was higher near sites that had higher-than-average abundance of breeding sage-grouse (Donnelly et al. 2017). Possible explanations for the lack of congruence between our findings and previous work include differences in the approach and spatial scale of the analyses. Sagebrush songbirds defend territories that are relatively 
Fig. 3. Relationships between Greater Sage-Grouse (Centrocercus urophasianus) and songbird abundance in central Wyoming, USA, 2012-2013. Greater Sage-Grouse abundance was quantified using a spatially explicit index of sage-grouse breeding population size (left column) and by counting fecal pellets along each transect (right column). Solid lines indicate the predicted songbird density in year 2013, and dashed lines indicate point-wise $95 \%$ confidence intervals based on a nonparametric bootstrap. Observed values for year 2013 are shown as transparent points to address overplotting; darker shades indicate multiple transects with the same values. See Table 1 for species scientific names.

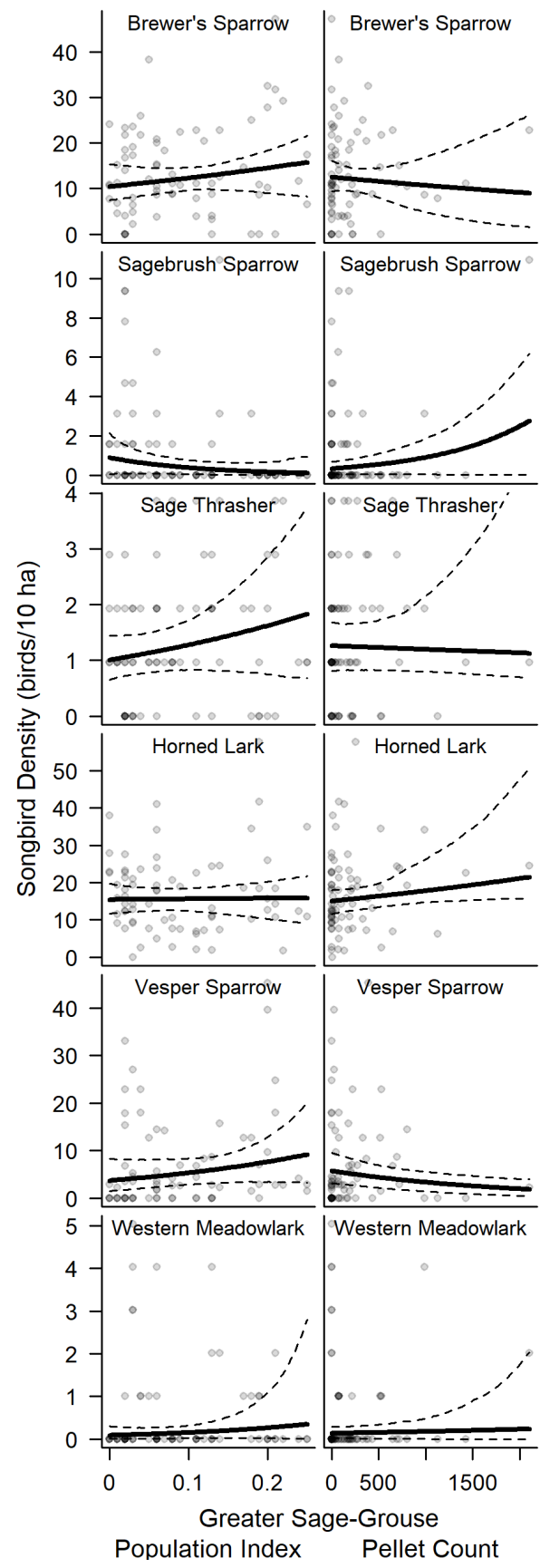

small in comparison to the scale at which sage-grouse use landscapes, and sagebrush songbirds exhibit microhabitat associations that differ from those of sage-grouse in some contexts (Chalfoun and Martin 2007, Connelly et al. 2011, Dinkins et al. 2016, Carlisle et al. 2018b, but see Barlow et al. 2020). Indeed, many analyses of sage-grouse habitat associations use pixel sizes of $30 \times 30 \mathrm{~m}$ (e.g., Timmer et al. 2019), at which scale a single pixel could comprise up to $20 \%$ of a Brewer's Sparrow territory (Rotenberry et al. 2020). Our study therefore helps reveal some of the finer scale relationships between sage-grouse and sagebrush songbird habitats. Furthermore, BBS data are collected at broad spatial extents via roadside routes by many different observers, and rigorous estimates of detection probabilities for many species have proven challenging (Smith et al. 2014). The use of BBS data for abundance comparisons at relatively fine spatial scales is therefore not ideal.

The sage-grouse indices we investigated also were unreliable proxies for the abundance of songbirds that use both sagebrush and grassland habitats. The limited dependency of grasslandassociated species on sagebrush habitats may explain the lack of concordance. The abundance of Horned Larks was slightly higher in areas with higher counts of sage-grouse fecal pellets, but Vesper Sparrows were less abundant in areas with more sage-grouse fecal pellets. Western Meadowlark abundance was unrelated to either index of sage-grouse abundance. Our results contrast with those of Rich et al. (2005) who found modest correlations in the abundances of Vesper Sparrow and Western Meadowlark with sage-grouse. The similar abundance patterns of Horned Larks and sage-grouse at our sites is somewhat counterintuitive given that sage-grouse are intimately tied to sagebrush habitats, whereas Horned Larks are often associated with more open (Skagen et al. 2018) or degraded (Gilbert and Chalfoun 2011, Bogard and Davis 2014) environments. Moreover, Horned Larks tend not to be the primary targets of conservation and management regimes in the sagebrush biome given their broad geographic distribution throughout North America and the Palearctic (Hof et al. 2017).

The directionality of the relationship between songbird and sagegrouse abundance was not consistent across the two indices of sage-grouse abundance for many of the species we studied. Although the pellet counts and population index were weakly and positively correlated, the difference in what these two indices represented biologically may explain the observed inconsistencies. The sage-grouse population index identified areas of high sagegrouse abundance and habitat suitability during the breeding season, based on the landscape characteristics surrounding lek locations (Doherty et al. 2016). By contrast, sage-grouse fecal pellets likely accumulate primarily outside the breeding season (Schroeder and Vander Haegen 2011) and can persist for several years (Boyce 1981). Our two sage-grouse indices therefore potentially represented the relative abundance of sage-grouse during distinct seasons (breeding and nonbreeding). The geographic areas and microhabitats occupied by sage-grouse can differ dramatically across seasons and life stages (Connelly et al. 2000,2011 ), and conservation efforts are typically prioritized on the basis of breeding-season habitats (U.S. Fish and Wildlife Service 2013, Chambers et al. 2017). Therefore, we suggest that researchers interested in assessing the efficacy of sage-grouse abundance as a surrogate for the abundance of other species carefully define the seasonal habitat(s) of sage-grouse likely to be 
most relevant to the comparator species within their study area. We reiterate, however, that at our sites and the scale at which we focused, neither index of sage-grouse abundance was a consistently reliable proxy for the local abundance of cooccurring passerine species of concern.

Sage-grouse management often takes the form of broad-scale efforts such as statewide regulations within sage-grouse core areas, or federal plans that prescribe management actions across relatively large regions (e.g., U.S. Fish and Wildlife Service 2015b). Broad-scale assessments of the surrogacy value of sage-grouse generally indicate that sage-grouse management is likely to benefit sagebrush-associated songbirds (Rowland et al. 2006, Hanser and Knick 2011, Donnelly et al. 2017, Carlisle et al. 2018a). Indeed, approximately $80 \%$ of our sampling frame was within the statedesignated core population area of sage-grouse (State of Wyoming 2011), which likely benefits all sagebrush-associated species to a certain extent by limiting the amount of surface disturbance (Gamo et al. 2013). However, sage-grouse management actions implemented locally can have unanticipated effects on other species (Norvell et al. 2014, Carlisle et al. 2018b). Land use decisions and habitat restoration activities for sagegrouse, moreover, often happen at multiple scales, suggesting the 10-15 ha areas considered here are relevant. Recent state-led efforts across the western U.S., for example, espouse the quantification of the value of sage-grouse habitat at relatively small spatial units via the use of a habitat quantification tool (HQT; Wyoming Conservation Exchange 2015, State of Montana 2018, State of Nevada 2020). In an HQT framework, sage-grouse habitat scores are estimated for each spatial unit, allowing the calculation of mitigation debits and restoration credits associated with anthropogenic activities, e.g., energy development or reclamation of vegetation. Notably, some HQTs prescribe the calculation of habitat scores within very small spatial units $(0.09$ ha in Wyoming [Wyoming Conservation Exchange 2015] and < 0.01 ha in Montana [State of Montana 2018]), creating an avenue for fine-scale land use decisions to be made based on the perceived value of those fine-scale areas to sage-grouse. Barlow et al. (2020) suggested that fine-scale conservation actions taken for sagegrouse would be beneficial, or at least inconsequential, for Brewer's Sparrows in the Powder River Basin of Wyoming based on congruence in nest-site selection between the two species there. However, the results of our multispecies study indicate that highabundance areas for sage-grouse and songbirds do not always correspond at fine spatial scales, suggesting that focusing on the conservation of fine-scale areas of high sage-grouse value would not likely benefit sagebrush-associated songbirds.

\section{CONCLUSION}

Although surrogate-species conservation strategies assume that different taxonomic groups show congruent patterns of distribution and abundance across space, there is mounting evidence to the contrary (Prendergast et al. 1993, Kerr 1997, Reid 1998, Grenyer et al. 2006). Ecological processes and habitat relationships often vary across spatial scales (Wiens 1989, Levin 1992), as do conservation problems and their appropriate solutions (du Toit 2010). Moreover, sagebrush-associated birds are well-known for scale-dependent habitat selection (Wiens et al. 1987, Chalfoun and Martin 2007, Connelly et al. 2011, Hanser and Knick 2011). Therefore, incongruence in a surrogate relationship at one scale, as shown here, does not necessarily signify incongruence at other scales. The challenge is to understand the limitations of the umbrella species concept, the contexts under which it constitutes a viable strategy, and when more targeted conservation efforts are necessary for particular focal species (Hanser and Knick 2011, Carlisle et al. 2018a, Dinkins and Beck 2019). A remaining frontier is to investigate the overlap between habitat quality for umbrella versus background species, to determine whether the areas that confer the highest fitness for the umbrella and other species are similar. Such inference is critical for the efficacy of management practices and sustainability of populations of concern.

Responses to this article can be read online at: http://www.ace-eco.org/issues/responses.php/1702

\section{Acknowledgments:}

Our study was funded by the Wyoming Game \& Fish Department and Wyoming Sage-grouse Local Working Groups. We thank A. M. Davis, D. P. Harvey, C. M. Laughlin, S. E. Trapp, K. J. Heitkamp, J. T. Lamperty, S. R. Opitz, C. S. Scholtz, and T. N. Smith for assistance conducting field surveys. We thank T. $L$. McDonald for insights on distance-sampling analysis and $K . T$. Smith and C. W. LeBeau for discussions on sage-grouse management. Members of the graduate committee for J. D. C., the Chalfoun lab group, and several anonymous reviewers provided thoughtful comments that improved this research. Any use of trade, firm, or product names is for descriptive purposes only and does not imply endorsement by the U.S. Government.

\section{LITERATURE CITED}

Andelman, S. J., and W. F. Fagan. 2000. Umbrellas and flagships: efficient conservation surrogates or expensive mistakes? Proceedings of the National Academy of Sciences of the United States of America 97:5954-5959. https://doi.org/10.1073/ pnas. 100126797

Andrewartha, H. G., and L. C. Birch. 1954. The distribution and abundance of animals. University of Chicago Press, Chicago, Illinois, USA.

Barlow, N. L., C. P. Kirol, K. E. Doherty, and B. C. Fedy. 2020. Evaluation of the umbrella species concept at fine spatial scales. Journal of Wildlife Management 84:237-248. https://doi. org/10.1002/jwmg.21791

Berger, J. 1997. Population constraints associated with the use of black rhinos as an umbrella species for desert herbivores. Conservation Biology 11:69-78. https://doi.org/10.1046/ j.1523-1739.1997.95481.x

Bivand, R. S., T. Keitt, and B. Rowlingson. 2018. rgdal: bindings for the Geospatial Data Abstraction Library. R package version 1.3-6. [online] URL: http://cran.r-project.org/package=rgdal

Bivand, R. S., and C. W. Rundel. 2018. rgeos: Interface to geometry engine - Open Source (GEOS). R package version 0.4-2. [online] URL: http://cran.r-project.org/package=rgeos 
Bogard, H. J. K., and S. K. Davis. 2014. Grassland songbirds exhibit variable responses to the proximity and density of natural gas wells. Journal of Wildlife Management 78:471-482. https://doi. org/10.1002/jwmg.684

Bolker, B. M., and R Core Team. 2017. bbmle: tools for general maximum likelihoodestimation. $\mathrm{R}$ package version 1.0.20. [online] URL: http://cran.r-project.org/package=bbmle

Boyce, M. S. 1981. Robust canonical correlation of Sage Grouse habitat. Pages 152-159 in D. Capen, editor. The use of multivariate statistics in studies of wildlife habitat. U.S. Forest Service General Technical Report RM-87, Fort Collins, Colorado, USA.

Branton, M. A., and J. S. Richardson. 2014. A test of the umbrella species approach in restored floodplain ponds. Journal of Applied Ecology 51:776-785. https://doi.org/10.1111/1365-2664.12248

Brooks, M. E., K. Kristensen, K. J. van Benthem, A. Magnusson, C. W. Berg, A. Nielsen, H. J. Skaug, M. Mächler, and B. M. Bolker. 2017. glmmTMB balances speed and flexibility among packages for zero-inflated generalized linear mixed modeling. $R$ Journal 9:378-400. https://doi.org/10.32614/RJ-2017-066

Buckland, S. T., D. R. Anderson, K. P. Burnham, J. L. Laake, D. L. Borchers, and L. Thomas. 2001. Introduction to distance sampling: estimating abundance of biological populations. Oxford University Press, Oxford, UK.

Buckland, S. T., E. A. Rexstad, T. A. Marques, and C. S. Oedekoven. 2015. Distance sampling: methods and applications. Springer, New York, New York, USA. https://doi. org/10.1007/978-3-319-19219-2

Buckland, S. T., R. E. Russell, B. G. Dickson, V. A. Saab, D. N. Gorman, and W. M. Block. 2009. Analyzing designed experiments in distance sampling. Journal of Agricultural, Biological, and Environmental Statistics 14:432-442. https://doi. org/10.1198/jabes.2009.08030

Bull, E. L. 1981. Indirect estimates of abundance of birds. Studies in Avian Biology 6:76-80.

Burnham, K. P., and D. R. Anderson. 2002. Model selection and multimodel inference: a practical information-theoretic approach. Second edition. Springer-Verlag, New York, New York, USA.

Carlisle, J. D., G. Bedrosian, and T. L. McDonald. 2017. The influence of Greater Sage-Grouse management on risks faced by Golden Eagles in sagebrush ecosystems: a spatially explicit assessment of the umbrella species concept. Prepared for Western Golden Eagle Team, U.S. Fish and Wildlife Service. Technical report, Western EcoSystems Technology, Inc., Laramie, Wyoming, USA.

Carlisle, J. D., A. D. Chalfoun, K. T. Smith, and J. L. Beck. $2018 b$. Nontarget effects on songbirds from habitat manipulation for Greater Sage-Grouse: implications for the umbrella species concept. Condor 120:439-455. https://doi.org/10.1650/condor-17-200.1

Carlisle, J. D., D. A. Keinath, S. E. Albeke, and A. D. Chalfoun. 2018a. Identifying holes in the Greater Sage-Grouse conservation umbrella. Journal of Wildlife Management 82:948-957. https:// doi.org/10.1002/jwmg.21460
Caro, T. M. 2003. Umbrella species: critique and lessons from East Africa. Animal Conservation 6:171-181. https://doi. org/10.1017/S1367943003003214

Caro, T. M. 2010. Conservation by proxy: indicator, umbrella, keystone, flagship, and other surrogate species. Island Press, Washington, D.C., USA.

Caughley, G. 1977. Analysis of vertebrate populations. John Wiley \& Sons, Chichester, West Sussex, UK.

Chalfoun, A. D., and T. E. Martin. 2007. Assessments of habitat preferences and quality depend on spatial scale and metrics of fitness. Journal of Applied Ecology 44:983-992. https://doi. org/10.1111/j.1365-2664.2007.01352.x

Chambers, J. C., J. L. Beck, J. B. Bradford, J. Bybee, J. Carlson, T. J. Christiansen, K. J. Clause, G. Collins, M. R. Crist, J. B. Dinkins, K. E. Doherty, F. Edwards, K. A. Griffin, P. Griffin, J. R. Haas, S. E. Hanser, D. W. Havlina, K. F. Henke, J. D. Hennig, L. A. Joyce, F. Kilkenny, S. M. Kulpa, L. L. Kurth, J. D. Maestas, M. Manning, K. E. Mayer, B. A. Mealor, C. Mccarthy, M. Pellant, M. A. Perea, K. L. Prentice, D. A. Pyke, L. A. Wiechman, and A. Wuenschel. 2017. Science framework for conservation and restoration of the sagebrush biome: linking the Department of the Interior's integrated rangeland fire management strategy to longterm strategic conservation actions. Part 1. Science basis and applications. U.S. Forest Service General Technical Report RMRS-GTR-360, Fort Collins, Colorado, USA.

Chambers, J. C., J. L. Beck, S. Campbell, J. Carlson, T. J. Christiansen, K. J. Clause, J. B. Dinkins, K. E. Doherty, K. A. Griffin, D. W. Havlina, K. F. Henke, J. D. Hennig, L. L. Kurth, J. D. Maestas, M. Manning, K. E. Mayer, B. A. Mealor, C. McCarthy, M. A. Perea, and D. A. Pyke. 2016. Using resilience and resistance concepts to manage threats to sagebrush ecosystems, Gunnison Sage-Grouse, and the Greater Sage-Grouse in their eastern range: a strategic multi-scale approach. U.S. Forest Service General Technical Report RMRS-GTR-356, Fort Collins, Colorado, USA.

Connelly, J. W., E. T. Rinkes, and C. E. Braun. 2011. Characteristics of Greater Sage-Grouse habitats: a landscape species at micro- and macroscales. Pages 69-83 in S. T. Knick and J. W. Connelly, editors. Greater Sage-Grouse: ecology and conservation of a landscape species and its habitats. University of California Press, Berkeley, California, USA. https://doi. org/10.1525/california/9780520267114.003.0005

Connelly, J. W., M. A. Schroeder, A. R. Sands, and C. E. Braun. 2000. Guidelines to manage sage grouse populations and their habitats. Wildlife Society Bulletin 28:967-985.

Copeland, H. E., H. Sawyer, K. L. Monteith, D. E. Naugle, A. Pocewicz, N. Graf, and M. J. Kauffman. 2014. Conserving migratory mule deer through the umbrella of sage-grouse. Ecosphere 5:1-16. https://doi.org/10.1890/ES14-00186.1

Cushman, S. A., K. S. McKelvey, B. R. Noon, and K. McGarigal. 2010. Use of abundance of one species as a surrogate for abundance of others. Conservation Biology 24:830-840. https:// doi.org/10.1111/j.1523-1739.2009.01396.x

Dahlgren, D. K., R. Chi, and T. A. Messmer. 2006. Greater SageGrouse response to sagebrush management in Utah. Wildlife 
Society Bulletin 34:975-985. https://doi.org/10.2193/0091-7648 (2006)34[975:GSRTSM]2.0.CO;2

Dinkins, J. B., and J. L. Beck. 2019. Comparison of conservation policy benefits for an umbrella and related sagebrush-obligate species. Human-Wildlife Interactions 13:447-458.

Dinkins, J. B., K. T. Smith, J. L. Beck, C. P. Kirol, A. C. Pratt, and M. R. Conover. 2016. Microhabitat conditions in Wyoming's Sage-Grouse core areas: effects on nest site selection and success. PLoS ONE 11(3):e0150798. https://doi.org/10.1371/journal. pone. 0150798

Doherty, K. E., J. S. Evans, P. S. Coates, L. M. Juliusson, and B. C. Fedy. 2016. Importance of regional variation in conservation planning: a rangewide example of the Greater Sage-Grouse. Ecosphere 7:e01462. https://doi.org/10.1002/ecs2.1462

Doherty, K. E., J. D. Tack, J. S. Evans, and D. E. Naugle. 2010. Mapping breeding densities of greater sage-grouse: a tool for rangewide conservation planning. Prepared for U.S. Bureau of Land Management (\#L10PG00911). Technical report, U.S. Fish and Wildlife Service, Bismark, North Dakota, USA.

Donnelly, J. P., J. D. Tack, K. E. Doherty, D. E. Naugle, B. W. Allred, and V. J. Dreitz. 2017. Extending conifer removal and landscape protection strategies from sage-grouse to songbirds, a range-wide assessment. Rangeland Ecology \& Management 70:95-105. https://doi.org/10.1016/j.rama.2016.10.009

du Toit, J. T. 2010. Considerations of scale in biodiversity conservation. Animal Conservation 13:229-236. https://doi. org/10.1111/j.1469-1795.2010.00355.x

Gamo, R. S., J. D. Carlisle, J. L. Beck, J. A. C. Bernard, and M. E. Herget. 2013. Greater Sage-Grouse in Wyoming: an umbrella species for sagebrush-dependent wildlife. Wildlife Professional 7:56-59.

Gesch, D. B., M. Oimoen, S. Greenlee, C. Nelson, M. Steuck, and D. Tyler. 2002. The national elevation dataset. Photogrammetric Engineering \& Remote Sensing 68:5-32.

Gilbert, M. M., and A. D. Chalfoun. 2011. Energy development affects populations of sagebrush songbirds in Wyoming. Journal of Wildlife Management 75:816-824. https://doi.org/10.1002/ jwmg. 123

Grenyer, R., C. D. L. Orme, S. F. Jackson, G. H. Thomas, R. G. Davies, T. J. Davies, K. E. Jones, V. A. Olson, R. S. Ridgely, P. C. Rasmussen, T.-S. Ding, P. M. Bennett, T. M. Blackburn, K. J. Gaston, J. L. Gittleman, and I. P. F. Owens. 2006. Global distribution and conservation of rare and threatened vertebrates. Nature 444:93-96. https://doi.org/10.1038/nature05237

Hanser, S. E., C. L. Aldridge, M. Leu, M. M. Rowland, S. E. Nielsen, and S. T. Knick. 2011. Greater Sage-Grouse: general use and roost site occurrence with pellet counts as a measure of relative abundance. Pages 112-140 in S. E. Hanser, M. Leu, S. T. Knick, and C. L. Aldridge, editors. Sagebrush ecosystem conservation and management: ecoregional assessment tools and models for the Wyoming Basins. Allen Press, Lawrence, Kansas, USA.

Hanser, S. E., and S. T. Knick. 2011. Greater sage-grouse as an umbrella species for shrubland passerine birds: a multiscale assessment. Pages 473-487 in S. T. Knick and J. W. Connelly, editors. Greater Sage-Grouse: ecology and conservation of a landscape species and its habitats. University of California Press, Berkeley, California, USA. https://doi.org/10.1525/ california/9780520267114.003.0020

Hijmans, R. J. 2018. raster: Geographic data analysis andmodeling. $\mathrm{R}$ package version 2.8-4. [online] URL: http://cran.r-project.org/ package $=$ raster

Hof, A. R., G. Rodríquez-Castañeda, A. M. Allen, R. Jansson, and C. Nilsson. 2017. Vulnerability of subarctic and arctic breeding birds. Ecological Applications 27:219-234. https://doi. org/10.1002/eap.1434

Homer, C. G., C. L. Aldridge, D. K. Meyer, and S. J. Schell. 2012. Multi-scale remote sensing sagebrush characterization with regression trees over Wyoming, USA: laying a foundation for monitoring. International Journal of Applied Earth Observation and Geoinformation 14:233-244. https://doi.org/10.1016/j. jag.2011.09.012

Karels, T. J., L. Koppel, and D. S. Hik. 2004. Fecal pellet counts as a technique for monitoring an alpine-dwelling social rodent, the hoary marmot (Marmota caligata). Arctic, Antarctic, and Alpine Research 36:490-494. https://doi.org/10.1657/1523-0430 (2004)036[0490:FPCAAT]2.0.CO;2

Kellner, K. F., and R. K. Swihart. 2014. Accounting for imperfect detection in ecology: a quantitative review. PLOS ONE9:e111436. https://doi.org/10.1371/journal.pone.0111436

Kerr, J. T. 1997. Species richness, endemism, and the choice of areas for conservation. Conservation Biology 11:1094-1100. https://doi.org/10.1046/j.1523-1739.1997.96089.x

Kéry, M. 2010. Introduction to WinBUGS for ecologists: a Bayesian approach to regression, ANOVA, mixed models and related analyses. Academic, Burlington, Massachusetts, USA.

Kéry, M., and M. Schaub. 2012. Bayesian population analysis using WinBUGS: a hierarchical perspective. Academic, Waltham, Massachusetts, USA. https://doi.org/10.1016/b978-0-12-387020-9.00001-8

Knaus, J. 2015. snowfall: Easier cluster computing (based on snow). R package version 1.84-6.1. [online] URL: http://cran.rproject.org/package $=$ snowfall

Knick, S. T., and J. W. Connelly, editors. 2011. Greater SageGrouse: ecology and conservation of a landscape species and its habitats. University of California Press, Berkeley, California, USA. https://doi.org/10.1525/9780520948686

Knick, S. T., D. S. Dobkin, J. T. Rotenberry, M. A. Schroeder, W. M. Vander Haegen, and C. van Riper III. 2003. Teetering on the edge or too late? Conservation and research issues for avifauna of sagebrush habitats. Condor 105:611-634. https://doi. org/10.1093/condor/105.4.611

Krausman, P. R. 2002. Introduction to wildlife management: the basics. Prentice Hall, Upper Saddle River, New Jersey, USA.

Krebs, C. J., B. S. Gilbert, S. Boutin, and R. Boonstra. 1987. Estimation of snowshoe hare population density from turd transects. Canadian Journal of Zoology 65:565-567. https://doi. org/10.1139/z87-087 
Levin, S. A. 1992. The problem of pattern and scale in ecology. Ecology 73:1943-1967. https://doi.org/10.2307/1941447

Maestas, J. D., S. B. Campbell, J. C. Chambers, M. Pellant, and R. F. Miller. 2016. Tapping soil survey information for rapid assessment of sagebrush ecosystem resilience and resistance. Rangelands 38:120-128. https://doi.org/10.1016/j.rala.2016.02.002

Manly, B. F. J. 2006. Randomization, bootstrap and Monte Carlo methods in biology. Third edition. Chapman \& Hall/CRC, London, UK.

McDonald, T. L., J. D. Carlisle, and A. McDonald. 2019. Rdistance: distance-sampling analyses for density and abundance estimation. R package version 2.1.3. [online] URL: http://cran.rproject.org $/$ package $=$ Rdistance

Molles Jr., M. C. 2005. Ecology: concepts and applications. Third edition. McGraw-Hill, New York, New York, USA.

Neff, D. J. 1968. The pellet-group count technique for big game trend, census, and distribution: a review. Journal of Wildlife Management 32:597-614. https://doi.org/10.2307/3798941

North American Bird Conservation Initiative. 2016. The state of North America's birds 2016. Environment and Climate Change Canada, Ottawa, Ontario, Canada.

Norvell, R. E., T. C. Edwards, and F. P. Howe. 2014. Habitat management for surrogate species has mixed effects on non-target species in the sagebrush steppe. Journal of Wildlife Management 78:456-462. https://doi.org/10.1002/jwmg.680

Paige, C., and S. A. Ritter. 1999. Birds in a sagebrush sea: managing sagebrush for bird communities. Partners in Flight Western Working Group, Boise, Idaho, USA. https://doi.org/10.5962/bhl. title. 141890

Pebesma, E. J., and R. S. Bivand. 2005. Classes and methods for spatial data in R. R News 5:9-13.

Prendergast, J. R., R. M. Quinn, J. H. Lawton, B. C. Eversham, and D. W. Gibbons. 1993. Rare species, the coincidence of diversity hotspots and conservation strategies. Nature 365:335-337. https://doi.org/10.1038/365335a0

PRISM Climate Group. 2012. 30-year normals. Oregon State University, Corvallis, Oregon, USA. [online] URL: https://prism. oregonstate.edu/normals/

R Core Team. 2018. $R$ : a language and environment for statistical computing. R Foundation for Statistical Computing, Vienna, Austria. [online] URL: https://www.R-project.org/

Reid, W. V. 1998. Biodiversity hotspots. Trends in Ecology \& Evolution 13:275-280. https://doi.org/10.1016/S0169-5347(98) 01363-9

Rich, T. D., and B. Altman. 2001. Under the sage-grouse umbrella. Bird Conservation 14:10.

Rich, T. D., M. J. Wisdom, and V. A. Saab. 2005. Conservation of priority birds in sagebrush ecosystems. U.S. Forest Service General Technical Report PSW-GTR-191, Albany, California, USA.

Rosenberg, K. V., A. M. Dokter, P. J. Blancher, J. R. Sauer, A. C. Smith, P. A. Smith, J. C. Stanton, A. Panjabi, L. Helft, M. Parr, and P. P. Marra. 2019. Decline of the North American avifauna. Science 366:120-124. https://doi.org/10.1126/science.aaw1313

Rosenberg, K. V., J. A. Kennedy, R. Dettmers, R. P. Ford, D. Reynolds, J. D. Alexander, C. J. Beardmore, P. J. Blancher, R. E. Bogart, G. S. Butcher, A. F. Camfield, A. Couturier, D. W. Demarest, W. E. Easton, J. J. Giocomo, R. H. Keller, A. E. Mini, A. O. Panjabi, D. N. Pashley, T. D. Rich, J. M. Ruth, H. Stabins, J. Stanton, and T. Will. 2016. Partners in Flight Landbird Conservation Plan: 2016 revision for Canada and Continental United States. Partners in Flight Science Committee.

Rotenberry, J. T., M. A. Patten, and K. L. Preston. 2020. Brewer's Sparrow (Spizella breweri), version 1.0. In A. F. Poole and F. B. Gill, editors. Birds of the world. Cornell Lab of Ornithology, Ithaca, New York, USA. https://doi.org/10.2173/bow.brespa.01

Rowland, M. M., M. J. Wisdom, L. H. Suring, and C. W. Meinke. 2006. Greater Sage-Grouse as an umbrella species for sagebrushassociated vertebrates. Biological Conservation 129:323-335. https://doi.org/10.1016/j.biocon.2005.10.048

Sauer, J. R., D. K. Niven, J. E. Hines, D. J. Ziolkowski, Jr, K. L. Pardieck, J. E. Fallon, and W. A. Link. 2017. The North American Breeding Bird Survey, results and analysis 1966 - 2015. Version 2.07.2017 USGS Patuxent Wildlife Research Center, Laurel, Maryland, USA.

Scheaffer, R. L., W. Mendenhall III, R. L. Ott, and K. G. Gerow. 2012. Elementary survey sampling. Seventh edition. Cengage Learning, Boston, Massachusetts, USA.

Schroeder, M. A., and W. M. Vander Haegen. 2011. Response of Greater Sage-Grouse to the conservation reserve program. Pages 517-529 in S. T. Knick and J. W. Connelly, editors. Greater SageGrouse: ecology and conservation of a landscape species and its habitats. University of California Press, Berkeley, California, USA. https://doi.org/10.1525/california/9780520267114.003.0023

Skagen, S. K., D. J. Augustine, and J. D. Derner. 2018. Semi-arid grassland bird responses to patch-burn grazing and drought. Journal of Wildlife Management 82:445-456. https://doi. org/10.1002/jwmg.21379

Simberloff, D. 1998. Flagships, umbrellas, and keystones: is single-species management passé in the landscape era? Biological Conservation 83:247-257. https://doi.org/10.1016/s0006-3207(97) 00081-5

Smith, A. C., M. R. Hudson, C. Downes, and C. M. Francis. 2014. Estimating breeding bird survey trends and annual indices for Canada: how do the new hierarchical Bayesian estimates differ from previous estimates? Canadian Field-Naturalist 128:119-128. https://doi.org/10.22621/cfn.v128i2.1565

State of Montana. 2018. Montana mitigation system habitat quantification tool technicalmanual for greater sage-grouse, version 1.0 October 2018. Montana Mitigation Stakeholder Team, Montana Sage-Grouse Conservation Program. Montana, USA. [online] URL: https://sagegrouse.mt.gov/documents/ MT_HQT_Oct2018v1p0_09Oct2018.pdf

State of Nevada. 2020. Habitat quantification tool: scientific methods document, version 1.6. Prepared for State of Nevada, Department of Conservation and Natural Resources, Sagebrush 
Ecosystem Program. Environmental Incentives, LLC and EcoMetrix Solutions Group, LLC, South Lake Tahoe, California, USA. [online] URL: http://sagebrusheco.nv.gov/uploadedFiles/ sagebrusheconvgov/content/CCS/NV $\% 20$ CCS $\% 20$ HQT $\% 20$ Methods $\%$ 20Document $\%$ 20Version $\% 201.4$.pdf

State of Wyoming. 2008. Greater Sage-Grouse core area protection. Office of Governor Freudenthal. State of Wyoming Executive Department Executive Order. 2008-2. Cheyenne, Wyoming, USA.

State of Wyoming. 2011. Greater Sage-Grouse core area protection. Office of Governor Mead. State of Wyoming Executive Department Executive Order. 2011-5. Cheyenne, Wyoming, USA.

State of Wyoming. 2015. Greater Sage-Grouse core area protection. Office of Governor Mead. State of Wyoming Executive Department Executive Order. 2015-4. Cheyenne, Wyoming, USA.

Stiver, S. J. 2011. The legal status of Greater Sage-Grouse: organizational structure of planning efforts. Pages 33-49 in S. T. Knick and J. W. Connelly, editors. Greater Sage-Grouse: ecology and conservation of a landscape species and its habitats. University of California Press, Berkeley, California, USA. https://doi. org/10.1525/california/9780520267114.003.0003

Tierney, L., A. J. Rossini, N. Li, and H. Sevcikova. 2016. snow: simple network of workstations. R package version 0.4-2. [online] URL: https://CRAN.R-project.org/package=snow

Timmer, J. M., C. L. Aldridge, and M. A. Fernández-Giménez. 2019. Managing for multiple species: Greater Sage-Grouse and sagebrush songbirds. Journal of Wildlife Management 83:1043-1056. https://doi.org/10.1002/jwmg.21663

U.S. Fish and Wildlife Service. 2013. Greater Sage-grouse (Centrocercus urophasianus) conservation objectives: Final report. U.S. Fish and Wildlife Service, Denver, Colorado, USA.

U.S. Fish and Wildlife Service. 2015a. Technical reference on using surrogate species for landscape conservation. U.S. Fish and Wildlife Service, Washington D.C., USA.

U.S. Fish and Wildlife Service. 2015b. Endangered and threatened wildlife and plants; 12 month finding on a petition to list greater sage-grouse (Centrocercus urophasianus) as an endangered or threatened species; proposed rule. Federal Register 80 (191):59858-59942. U.S. Fish and Wildlife Service, Denver, Colorado, USA.

White, G. C. 2005. Correcting wildlife counts using detection probabilities. Wildlife Research 32:211-216. https://doi.org/10.1071/ WR03123

Wiens, J. A. 1989. Spatial scaling in ecology. Functional Ecology 3:385-397. https://doi.org/10.2307/2389612
Wiens, J. A., J. T. Rotenberry, and B. Van Horne. 1987. Habitat occupancy patterns of North American shrubsteppe birds: the effects of spatial scale. Oikos 48:132-147. https://doi. org/10.2307/3565849

Wyoming Conservation Exchange. 2015. Greater Sage-Grouse habitat quantification tool: a multi-scaled approach for assessing impacts and benefits to greater sage-grouse habitat, scientific methods document, version 3. Wyoming Conservation Exchange, Sheridan, Wyoming, USA. [online] URL: http://www. wyomingconservationexchange.org/wp-content/uploads/2014/08/ WY_Sage_Grouse_HQT_May01_2015.pdf

Zuur, A. F., E. N. Ieno, N. J. Walker, A. A. Saveliev, and G. M. Smith. 2009. Mixed effects models and extensions in ecology with $R$. Springer Science \& Business Media, New York, New York, USA. https://doi.org/10.1007/978-0-387-87458-6
Editor-in-Chief: Keith A.Hobson Subject Editor: Brad Fedy
Sponsored by the Society of Canadian Ornithologists and Birds Canada

Parrainée par la Société des ornithologistes du Canada et Oiseaux Canada 


\section{Appendix 1. AICc tables for detection modeling}

The abundance of Greater Sage-Grouse as a proxy for the abundance of sagebrush-associated songbirds in Wyoming, USA

Tables detailing the AICc model-selection results for the detection-modeling stage of the analysis (stage 1). Distance-sampling models were fit to songbird data collected during 144 surveys in central Wyoming, USA, 2012-2013. The key function fit to the distance data and the covariates on the shape parameter in the detection function varied by model. 
Table A1.1. Model-selection results comparing candidate distance-sampling models to estimate Brewer's Sparrow detectability $(P)$ in central Wyoming, USA, 2012-2013.

\begin{tabular}{lccccc}
\hline \hline Model & Key $^{\dagger}$ & $\mathbf{K}^{\ddagger}$ & $\mathbf{A I C c}^{\S}$ & $\Delta \mathbf{A I C} \mathbf{c}^{\mathbf{}}$ & $\boldsymbol{w}^{\mathbb{\Phi}}$ \\
\hline$P \sim$ BareGround + Observer & half-normal & 11 & 6605.88 & 0.00 & 0.94 \\
$P \sim$ Observer & half-normal & 10 & 6611.26 & 5.39 & 0.06 \\
$P \sim$ BareGround + Observer & hazard rate & 12 & 6620.05 & 14.17 & 0.00 \\
$P \sim$ BareGround & half-normal & 2 & 6623.58 & 17.70 & 0.00 \\
$P \sim$ Observer & hazard rate & 11 & 6623.68 & 17.81 & 0.00 \\
$P \sim 1$ & half-normal & 1 & 6626.10 & 20.22 & 0.00 \\
$P \sim$ BareGround & hazard rate & 3 & 6627.26 & 21.38 & 0.00 \\
$P \sim 1$ & hazard rate & 2 & 6628.28 & 22.40 & 0.00 \\
\hline
\end{tabular}

${ }^{\dagger}$ Key function describing the form of the distance-detection relationship.

${ }^{\ddagger}$ Number of parameters.

${ }^{\S}$ Second-order variant of Akaike's Information Criterion.

'Difference in AICc between the model and the top-ranked model in the set.

IIModel weight. 
Table A1.2. Model-selection results comparing candidate distance-sampling models to estimate Sagebrush Sparrow detectability $(P)$ in central Wyoming, USA, 2012-2013.

\begin{tabular}{lccccc}
\hline \hline Model & Key $^{\dagger}$ & $\mathbf{K}^{\ddagger}$ & $\mathbf{A I C c}^{\mathbf{8}}$ & $\mathbf{\Delta A I C \mathbf { c } ^ { \mathbf { 1 } }}$ & $\boldsymbol{w}^{\text {II }}$ \\
\hline$P \sim 1$ & half-normal & 1 & 615.64 & 0.00 & 0.77 \\
$P \sim 1$ & hazard rate & 2 & 618.01 & 2.37 & 0.23 \\
\hline
\end{tabular}

${ }^{\ddagger}$ Key function describing the form of the distance-detection relationship.

tNumber of parameters.

${ }^{\S}$ Second-order variant of Akaike's Information Criterion.

'Difference in AICc between the model and the top-ranked model in the set.

Model weight. 
Table A1.3. Model-selection results comparing candidate distance-sampling models to estimate Sage Thrasher detectability $(P)$ in central Wyoming, USA, 2012-2013.

\begin{tabular}{lccccc}
\hline Model & Key $^{\dagger}$ & $\mathbf{K}^{\dagger}$ & $\mathbf{A I C c}^{\S}$ & $\boldsymbol{\Delta A I C \mathbf { c } ^ { \mathbf { 1 } }}$ & $\boldsymbol{w}^{\mathrm{II}}$ \\
\hline$P \sim 1$ & hazard rate & 2 & 1573.13 & 0.00 & 0.39 \\
$P \sim$ BareGround & hazard rate & 3 & 1573.31 & 0.18 & 0.36 \\
$P \sim 1$ & half-normal & 1 & 1575.04 & 1.90 & 0.15 \\
$P \sim$ BareGround & half-normal & 2 & 1575.98 & 2.85 & 0.09 \\
\hline
\end{tabular}

${ }^{\dagger}$ Key function describing the form of the distance-detection relationship.

Number of parameters.

${ }^{\S}$ Second-order variant of Akaike's Information Criterion.

Difference in AICc between the model and the top-ranked model in the set.

II Model weight. 
Table A1.4. Model-selection results comparing candidate distance-sampling models to estimate Horned Lark detectability $(P)$ in central Wyoming, USA, 2012-2013.

\begin{tabular}{|c|c|c|c|c|c|}
\hline Model & Key $^{\dagger}$ & $\mathbf{K}^{\dagger}$ & $\mathrm{AICc}^{\S}$ & $\Delta \mathrm{AICC}$ & $w^{\text {TI }}$ \\
\hline$P \sim$ BareGround + Observer & hazard rate & 12 & 8336.00 & 0.00 & 0.44 \\
\hline$P \sim$ Observer & hazard rate & 11 & 8336.23 & 0.24 & 0.39 \\
\hline$P \sim$ Observer & half-normal & 10 & 8338.61 & 2.62 & 0.12 \\
\hline$P \sim$ BareGround + Observer & half-normal & 11 & 8339.95 & 3.95 & 0.06 \\
\hline$P \sim 1$ & hazard rate & 2 & 8399.49 & 63.49 & 0.00 \\
\hline$P \sim$ BareGround & hazard rate & 3 & 8400.37 & 64.37 & 0.00 \\
\hline$P \sim 1$ & half-normal & 1 & 8404.72 & 68.72 & 0.00 \\
\hline$P \sim$ BareGround & half-normal & 2 & 8405.96 & 69.96 & 0.00 \\
\hline
\end{tabular}

${ }^{\dagger}$ Key function describing the form of the distance-detection relationship.

${ }^{\ddagger}$ Number of parameters.

${ }^{\S}$ Second-order variant of Akaike's Information Criterion.

'Difference in AICc between the model and the top-ranked model in the set.

IIModel weight. 
Table A1.5. Model-selection results comparing candidate distance-sampling models to estimate Vesper Sparrow detectability $(P)$ in central Wyoming, USA, 2012-2013.

\begin{tabular}{lccccc}
\hline \hline Model & Key $^{\dagger}$ & $\mathbf{K}^{\ddagger}$ & $\mathbf{A I C c}^{\S}$ & $\Delta \mathbf{A I C c}$ & $\boldsymbol{w}^{\text {II }}$ \\
\hline$P \sim$ Observer & half-normal & 10 & 3148.50 & 0.00 & 0.42 \\
$P \sim$ BareGround + Observer & half-normal & 11 & 3148.85 & 0.35 & 0.35 \\
$P \sim$ Observer & hazard rate & 11 & 3150.39 & 1.89 & 0.16 \\
$P \sim$ BareGround + Observer & hazard rate & 12 & 3152.03 & 3.53 & 0.07 \\
$P \sim$ BareGround & half-normal & 2 & 3171.79 & 23.29 & 0.00 \\
$P \sim 1$ & half-normal & 1 & 3173.54 & 25.04 & 0.00 \\
$P \sim$ BareGround & hazard rate & 3 & 3175.74 & 27.24 & 0.00 \\
$P \sim 1$ & hazard rate & 2 & 3176.05 & 27.55 & 0.00 \\
\hline
\end{tabular}

${ }^{\dagger}$ Key function describing the form of the distance-detection relationship.

${ }^{\ddagger}$ Number of parameters.

${ }^{\S}$ Second-order variant of Akaike's Information Criterion.

'Difference in AICc between the model and the top-ranked model in the set.

IIModel weight. 
Table A1.6. Model-selection results comparing candidate distance-sampling models to estimate Western Meadowlark detectability $(P)$ in central Wyoming, USA, 2012-2013.

\begin{tabular}{lccccc}
\hline \hline Model & Key $^{\dagger}$ & $\mathbf{K}^{\ddagger}$ & AICc $^{\S}$ & $\Delta \mathbf{A I C} \mathbf{c}^{\mathbf{1}}$ & $\boldsymbol{w}^{\mathrm{qI}}$ \\
\hline$P \sim 1$ & half-normal & 1 & 534.64 & 0.00 & 0.70 \\
$P \sim 1$ & hazard rate & 2 & 536.33 & 1.69 & 0.30 \\
\hline
\end{tabular}

${ }^{\dagger}$ Key function describing the form of the distance-detection relationship.

Number of parameters.

${ }^{\S}$ Second-order variant of Akaike's Information Criterion.

'Difference in AICc between the model and the top-ranked model in the set.

II Model weight. 


\section{Appendix 2. AICc tables for abundance modeling}

The abundance of Greater Sage-Grouse as a proxy for the abundance of sagebrush-associated songbirds in Wyoming, USA

Tables detailing the AICc model-selection results for the abundance-modeling stage of the analysis (stage 2). Generalized linear mixed models (GLMMs) were fit to songbird data collected during 144 surveys in central Wyoming, USA, 2012-2013. The distribution assumed in the GLMM varied by model, but the same fixed and random effects were included in all models. 
Table A2.1. Model-selection results comparing candidate generalized linear mixed models to estimate Brewer's Sparrow abundance $(N)$ in central Wyoming, USA, 2012-2013. All models included the probability of detection estimated in stage 1 of the analysis as an offset term to effectively model songbird density corrected for detectability.

\begin{tabular}{|c|c|c|c|c|c|}
\hline Model & Distribution $^{\dagger}$ & $\mathbf{K}^{*}$ & $\mathrm{AICc}^{8}$ & $\Delta \mathrm{AICl}^{\mathrm{l}}$ & $w^{\text {II }}$ \\
\hline $\begin{aligned} N \sim & \text { PopulationIndex + PelletCount } \\
& + \text { Year }+ \text { (1|Cluster })\end{aligned}$ & ZINB & 7 & 777.52 & 0.00 & 1.00 \\
\hline $\begin{aligned} N & \sim \text { PopulationIndex }+ \text { PelletCount } \\
& + \text { Year + (1|Cluster })\end{aligned}$ & NB & 6 & 788.14 & 10.62 & 0.00 \\
\hline $\begin{aligned} N & \sim \text { PopulationIndex + PelletCount } \\
& + \text { Year + (1|Cluster })\end{aligned}$ & ZIP & 6 & 798.53 & 21.02 & 0.00 \\
\hline $\begin{aligned} N & \sim \text { PopulationIndex }+ \text { PelletCount } \\
& + \text { Year + (1|Cluster })\end{aligned}$ & $\mathrm{P}$ & 5 & 842.37 & 64.85 & 0.00 \\
\hline
\end{tabular}

${ }^{\top}$ Distribution assumed for the response variable. $\mathrm{P}=$ Poisson, $\mathrm{NB}=$ Negative Binomial, $\mathrm{ZIP}=$ zero-inflated Poisson, ZINB = zero-inflated Negative Binomial.

Number of parameters.

${ }^{\S}$ Second-order variant of Akaike's Information Criterion.

'Difference in AICc between the model and the top-ranked model in the set.

${ }^{\mathbb{T}}$ Model weight. 
Table A2.4. Model-selection results comparing candidate generalized linear mixed models to estimate Horned Lark abundance $(N)$ in central Wyoming, USA, 2012-2013. All models included the probability of detection estimated in stage 1 of the analysis as an offset term to effectively model songbird density corrected for detectability.

\begin{tabular}{|c|c|c|c|c|c|}
\hline Model & Distribution $^{\dagger}$ & $\mathbf{K}^{\ddagger}$ & $\mathrm{AICc}^{\S}$ & $\Delta \mathrm{AICc^{l }}$ & $w^{\text {II }}$ \\
\hline $\begin{aligned} N & \sim \text { PopulationIndex }+ \text { PelletCount } \\
& + \text { Year }+(1 \mid \text { Cluster })\end{aligned}$ & ZINB & 7 & 864.48 & 0.00 & 1.00 \\
\hline $\begin{aligned} N & \sim \text { PopulationIndex }+ \text { PelletCount } \\
& + \text { Year }+(1 \mid \text { Cluster })\end{aligned}$ & NB & 6 & 875.13 & 10.65 & 0.00 \\
\hline $\begin{aligned} N & \sim \text { PopulationIndex }+ \text { PelletCount } \\
& + \text { Year }+(1 \mid \text { Cluster })\end{aligned}$ & ZIP & 6 & 936.75 & 72.27 & 0.00 \\
\hline $\begin{aligned} N & \sim \text { PopulationIndex }+ \text { PelletCount } \\
& + \text { Year }+(1 \mid \text { Cluster })\end{aligned}$ & $\mathrm{P}$ & 5 & 990.57 & 126.09 & 0.00 \\
\hline
\end{tabular}

${ }^{\dagger}$ Distribution assumed for the response variable. $\mathrm{P}=$ Poisson, $\mathrm{NB}=$ Negative Binomial, $\mathrm{ZIP}=$ zero-inflated Poisson, ZINB = zero-inflated Negative Binomial.

Number of parameters.

${ }^{\S}$ Second-order variant of Akaike's Information Criterion.

'Difference in AICc between the model and the top-ranked model in the set.

"Model weight. 
Table A2.5. Model-selection results comparing candidate generalized linear mixed models to estimate Vesper Sparrow abundance $(N)$ in central Wyoming, USA, 2012-2013. All models included the probability of detection estimated in stage 1 of the analysis as an offset term to effectively model songbird density corrected for detectability.

\begin{tabular}{|c|c|c|c|c|c|}
\hline Model & Distribution $^{\dagger}$ & $\mathbf{K}^{\dagger}$ & $\mathrm{AICc}^{\S}$ & $\Delta \mathrm{AICC}$ & $w^{\text {TI }}$ \\
\hline $\begin{aligned} N & \sim \text { PopulationIndex }+ \text { PelletCount } \\
& + \text { Year }+(1 \mid \text { Cluster })\end{aligned}$ & NB & 6 & 607.39 & 0.00 & 0.75 \\
\hline $\begin{aligned} N & \sim \text { PopulationIndex }+ \text { PelletCount } \\
& + \text { Year }+(1 \mid \text { Cluster })\end{aligned}$ & ZINB & 7 & 609.60 & 2.21 & 0.25 \\
\hline $\begin{aligned} N & \sim \text { PopulationIndex }+ \text { PelletCount } \\
& + \text { Year }+(1 \mid \text { Cluster })\end{aligned}$ & ZIP & 6 & 690.92 & 83.53 & 0.00 \\
\hline $\begin{aligned} N & \sim \text { PopulationIndex }+ \text { PelletCount } \\
& + \text { Year }+(1 \mid \text { Cluster })\end{aligned}$ & $\mathrm{P}$ & 5 & 755.89 & 148.50 & 0.00 \\
\hline
\end{tabular}

${ }^{\dagger}$ Distribution assumed for the response variable. $\mathrm{P}=$ Poisson, $\mathrm{NB}=$ Negative Binomial, $\mathrm{ZIP}=$ zero-inflated Poisson, ZINB = zero-inflated Negative Binomial.

Number of parameters.

${ }^{\S}$ Second-order variant of Akaike's Information Criterion.

'Difference in AICc between the model and the top-ranked model in the set.

"Model weight. 
Table A2.6. Model-selection results comparing candidate generalized linear mixed models to estimate Western Meadowlark abundance $(N)$ in central Wyoming, USA, 2012-2013. All models included the probability of detection estimated in stage 1 of the analysis as an offset term to effectively model songbird density corrected for detectability.

\begin{tabular}{|c|c|c|c|c|c|}
\hline Model & Distribution $^{\dagger}$ & $\mathbf{K}^{*}$ & $\mathrm{AICc}^{\S}$ & $\Delta \mathrm{AAICc^{l }}$ & $w^{\text {II }}$ \\
\hline $\begin{array}{l}N \sim \text { PopulationIndex }+ \text { PelletCount } \\
\quad+\text { Year }+(1 \mid \text { Cluster })\end{array}$ & $\mathrm{P}$ & 5 & 196.61 & 0.00 & 0.55 \\
\hline $\begin{aligned} N & \sim \text { PopulationIndex }+ \text { PelletCount } \\
& + \text { Year }+(1 \mid \text { Cluster })\end{aligned}$ & NB & 6 & 198.66 & 2.05 & 0.20 \\
\hline $\begin{aligned} N & \sim \text { PopulationIndex }+ \text { PelletCount } \\
& + \text { Year }+(1 \mid \text { Cluster })\end{aligned}$ & ZIP & 6 & 198.78 & 2.18 & 0.19 \\
\hline $\begin{aligned} N & \sim \text { PopulationIndex }+ \text { PelletCount } \\
& + \text { Year }+(1 \mid \text { Cluster })\end{aligned}$ & ZINB & 7 & 200.87 & 4.26 & 0.07 \\
\hline
\end{tabular}

${ }^{\dagger}$ Distribution assumed for the response variable. $\mathrm{P}=$ Poisson, $\mathrm{NB}=$ Negative Binomial, $\mathrm{ZIP}=$ zero-inflated Poisson, ZINB = zero-inflated Negative Binomial.

Number of parameters.

${ }^{\S}$ Second-order variant of Akaike's Information Criterion.

'Difference in AICc between the model and the top-ranked model in the set.

"Model weight. 